\title{
A Design Alternative to Improve the Interconnection Capability of New Distributed-Generation Installations into Existing Griddle
}

\author{
José Agüero-Rubio ${ }^{1, *}$, Javier López-Martínez ${ }^{2}$, José Ignacio Rojas-Sola ${ }^{3}$ and \\ Ángel Jesús Callejón-Ferre ${ }^{4}$ \\ 1 Department of Electricity, IES Alhamilla of Almería, Almería 04005, Spain \\ 2 Zayin Technology, PITA Technology Park, Almería 04120, Spain; javier.lopez@zayintec.com \\ 3 Department of Engineering Graphics, Design and Projects, University of Jaén, Jaén 23071, Spain; \\ jirojas@ujaen.es \\ 4 Laboratory-Observatory Andalusian Working Conditions in the Agricultural Sector, Almería 04120, Spain; \\ acallejonferre@gmail.com \\ * Correspondence: jaguerorubio@gmail.com; Tel.: +34-617-449-428
}

Academic Editor: Francisco Manzano Agugliaro

Received: 12 April 2016; Accepted: 19 May 2016; Published: 27 May 2016

\begin{abstract}
Most distributed-generation facilities are performed on pre-built distribution grids. The design conditions of these existing grids may limit the ability of new users to get a connection due to technical and/or cost constraints. This work proposes a simple solution, adjusted to the relevant regulations and embodied in a radial distribution grid of Spanish low voltage, to improve the interconnection of distributed generation, usually grid connected photovoltaic systems. The proposed solution, based on increasing the section of the neutral line, achieves a capacity of increasing the length of the supply grid by more than $20 \%$.
\end{abstract}

Keywords: distribution grids; distributed generation; low voltage feeders; grid-connected; installation efficiency; sustainable cities

\section{Introduction}

According to previous studies [1,2], the production of renewable energy sources (RES) in Europe, and more specifically in Spain [3], will increase their portion of the total energy consumption from $10.5 \%$ in 2008 to $22.7 \%$ in 2020 . Because of this, it has been emphasized that if Europe wants to achieve its target to keep the global mean temperature increment below $2{ }^{\circ} \mathrm{C}$, it has to strive for a $100 \%$ renewable electricity system by 2050 [4].

It has been stated that the option of expanding solar as well as wind energy is viable in Spain [5-7], as the former could rise $30 \%$ and the latter $15 \%$ with reasonable costs between 2020 and 2030 . The cost of wind energy could be $7 \mathrm{c} € \cdot \mathrm{kWh}^{-1}$ with an investment cost between 860 and $920 € \cdot \mathrm{kW}^{-1}$, while the cost of photovoltaic solar energy would be around $12.9 \mathrm{c} € \cdot \mathrm{kWh}^{-1}$ with an investment cost of $0.15 € \cdot \mathrm{W}^{-1}$.

The present work examines photovoltaic grid-connected systems (PVGCSs), though it can be applied to other distributed generation (DG) technologies. The increase in the distributed-generation capacity means economic profits well as technical benefits [8-10]. In the case of overloaded grids, the proper inclusion of distributed generation would improve the load of the grid and limit the possibility of supply collapses [11-13]. The optimal location and size may serve multiple objectives such as reducing grid losses, updating the net value of production, and the knowledge of the distance to the point of collapse [14-19]. 
In Spain, PVGCSs have greatly expanded since the year 2004, owing to such regulations as the Royal Decree (RD) 436/2004 [20] and RD 661/2007 [21], though at present there is a lag in the number of new connections [22]. Nevertheless, the rise in electric costs as well as the fall in the price of the peak watt in photovoltaic panels will make photovoltaic installations cost effective by 2016 [23]. In addition, projects such as "Smart City", implemented in Malaga (Spain) are focused on the integration of renewable resources in low- and medium-voltage (LV and MV) distribution grids [24].

Most PVGCSs are connected to an existing distribution grid. In most cases, to connect a new installation it is required to reinforcement the existing grid or build a new one. In the present work, we propose a solution for increasing the maximum length of existing radial low-voltage feeders in order to encourage the inclusion of new users or DG installations.

The work is structured as follows: Section 2 poses the problem with its previous hypotheses and describes the method of normalized calculation as well as the solution proposed. Sections 3 and 4 present the results and their discussion, respectively, while Section 5 offers the conclusions.

\section{Problem Statement}

Papaioannou and Purvins [25] consider the DG generators as negative loads in radial LV feeders. In the present work, the study case is similar, but the intent is to increase the length of the distribution grid and therefore improve the connection capacity of the DG. As reflected in Figure 1, we considered a radial grid with any configuration of connected loads, nodes 1 to $\mathrm{N}$, keeping the node 0 for the feed through a step-down transformer. The problem consists of including a new node $N+1$ where connecting distributed generation and/or new users, implying a lengthening of the distribution grid of LV, according to Equation (1) and Figure 1.

$$
\Delta L=L_{N+1}-L_{N}
$$

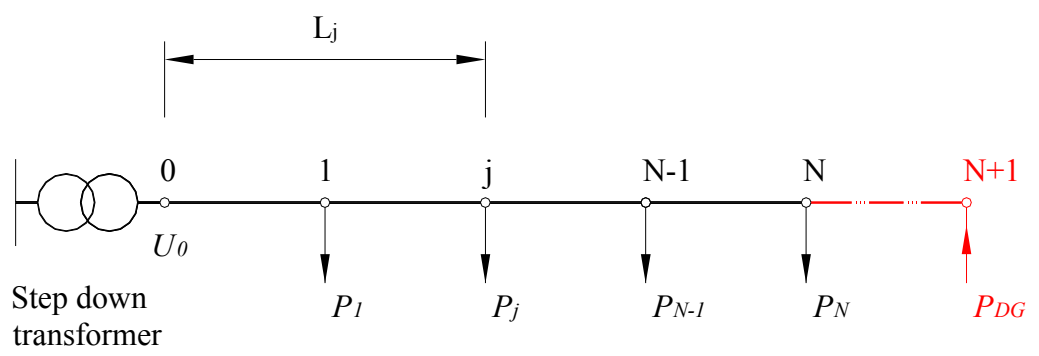

Figure 1. Radial low-tension distribution grid with increased length to include distributed generation (DG).

\subsection{Hypotheses}

The hypotheses of operation are established as follows:

- Distribution grid with only one load, i.e., $\mathrm{N}$ equal to 1 according to Figure 1, for the simplicity of the grid.

- The level of the previous load implies the maximum intensity reached by the overloads in the line.

- The coefficients for voltage drops, $C_{t}$, and resistance increase by temperature in the case of a short circuit, $C_{R}$, are fitted to the recommendations of the electric-grid designers [26], commonly 0.8 and 1.5 , respectively.

- The maximum length of the grid is limited by the lower intensity of the short circuit, i.e., the maximum length according to the condition of the voltage drop is larger than the maximum length according to the condition of the short circuit.

- The calculations are applied to distribution grids in balanced low voltage and it is considered to be a single-phase equivalent circuit [27]. 
- For the numerical analysis, a LV underground feeder is used according to the normative RD 842/2002 [28] and specific rules of the distribution company [29] (Figure 2).

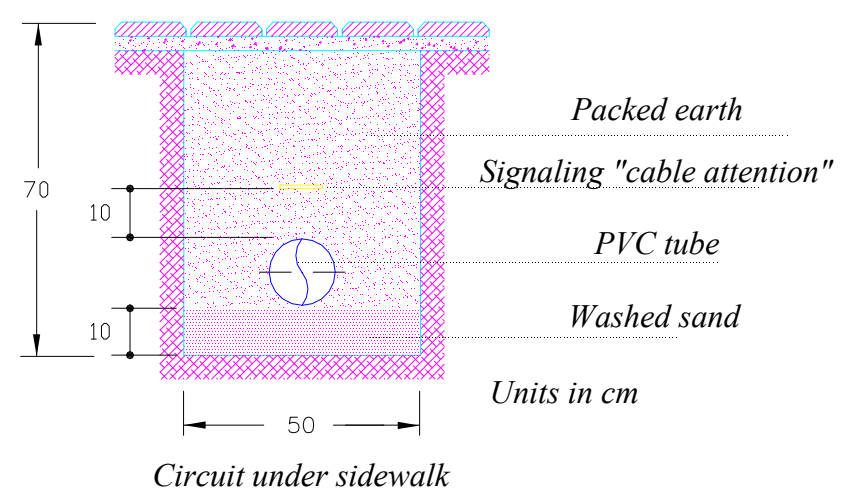

Figure 2. Example of underground distribution grid.

\subsection{Normalized Calculation Method}

Next, the design procedure for low-voltage distribution grids is described. International design guides were consulted [30], as well as Spanish ones [26]. For the following calculations, the single-phase equivalent circuit of the distribution grid was used (Figure 3). The design procedure is standardized according to the International Electro-technical Committee (IEC) under Spanish regulations according to the normative [28].

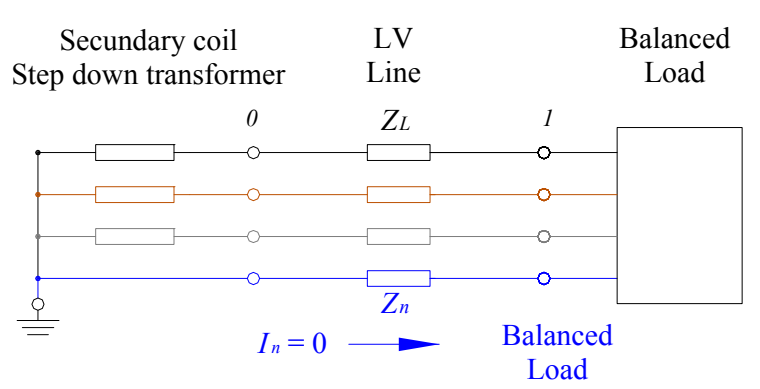

(a)

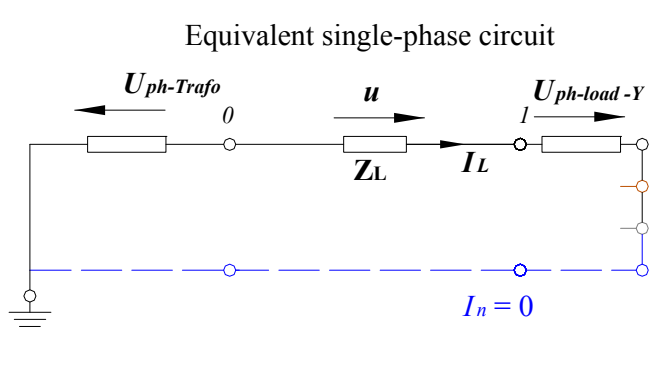

(b)

Figure 3. (a) Secondary equivalent circuit and the low-voltage (LV) distribution grid; (b) single-phase equivalent.

\subsubsection{Calculation for Voltage Drop}

The maximum voltage drop, e, recommended for a distribution grid at LV is established at 5\% [22], calculated according to Equation (2):

$$
\begin{aligned}
& e=e(\%) \cdot \frac{U_{L}}{100} \\
& e \geqslant u_{L}=\frac{P_{C}}{U_{L}}\left(R_{L}+X_{L} \cdot \tan \varphi\right)
\end{aligned}
$$

The length limitation established by the condition of the voltage drop, $L_{M a x-v d}$, is determined in Equation (3):

$$
\begin{aligned}
& L_{M a x-v d} \leqslant \frac{U_{L} \cdot e}{P_{C} \cdot\left(R_{u}+X_{u} \cdot \tan \varphi\right)} \\
& R_{u}=\frac{1}{K \cdot S}
\end{aligned}
$$

where the conductivity, $K$, is determined according to Table 1 , since it is a function of temperature of the maximum permanent regime and a function of insulation (Table 2). 
Table 1. Conductivity, $K$, as a function of temperature of the permanent regime of the insulation.

\begin{tabular}{ccc}
\hline Conductor & $K_{P V C}\left(\Omega^{-\mathbf{1}} \cdot \mathbf{m} \cdot \mathbf{m m}^{-\mathbf{2}}\right)$ at $\mathbf{7 0}{ }^{\circ} \mathrm{C}$ & $K_{X L P E}\left(\Omega^{-\mathbf{1}} \cdot \mathbf{m} \cdot \mathbf{m m}^{-\mathbf{2}}\right)$ at $\mathbf{9 0}{ }^{\circ} \mathrm{C}$ \\
\hline Copper $(\mathrm{Cu})$ & 48 & 44 \\
Aluminum $(\mathrm{Al})$ & 30 & 28 \\
\hline
\end{tabular}

Table 2. Temperature of the permanent regime according to the type of insulation.

\begin{tabular}{cc}
\hline Insulation & $\boldsymbol{T}_{\mathbf{r p}}\left({ }^{\circ} \mathbf{C}\right)$ \\
\hline PVC & 70 \\
XLPE & 90 \\
EPR & 90 \\
\hline
\end{tabular}

Notes: PVC stands for polyvinylchloride, XLPE for reticulated polyethylene and EPR for ethylenepropylene.

\subsubsection{Over Current, Calculation of Protections and Overloads}

Any circuit to be protected from the effects of over currents must comply with the IEC 60364-4-43:2008/Corr.:2008 [31]. These over currents may be originated due to: (i) overloads and (ii) short circuits.

According to the mentioned IEC 60364-4-43:2008/Corr.:2008, to guard against overloads in electrical installations, protection should be coordinated with the channeling of the circuit to be protected. To achieve this, the following conditions must be met:

$$
I_{B} \leqslant I_{N} \leqslant I_{Z} \text { and } I_{2} \leqslant 1.45 \cdot I_{z}
$$

where $I_{B}$ is the intensity of the line, calculated as:

$$
I_{B}=\frac{P_{C}}{\sqrt{3} \cdot U_{L} \cdot \cos \varphi}
$$

and $I_{N}$ is the nominal intensity of the protection device. The maximum admissible intensity of the channeling, $I_{Z}$, is that by which the conductor and therefore the insulation reaches the permanent regime temperature referred to in Table 2 [32].

If the environmental temperature or the installation conditions of the line are now different from that mentioned in the regulations, correction factors must be applied:

$$
I_{Z}=I_{t b} \cdot F c t \cdot F c i
$$

In Equation (4), $I_{2}$ is the effective functioning intensity of the protection device. The distribution grids are protected with fuses and, therefore, the effective functioning consists of its fusion, where its value is determined by Equation (7) [33].

$$
I_{2}=1.6 \cdot I_{N} ; \text { to }: I_{N} \geqslant 16 \mathrm{~A}
$$

\subsubsection{Over Current, Calculation of Protections and Short Circuits}

A short circuit is a clear defect, null-defect impedance, which causes high intensities with respect to the intensity of the permanent regime of the line, triggering spikes of dangerous temperatures for the installation. If the design of the installation is correct, a short circuit takes the wire to its maximum short-circuit temperature (Table 3) in $5 \mathrm{~s}$. 
Table 3. Short-circuit temperature for each type of insulation.

\begin{tabular}{cc}
\hline Insulation & $\boldsymbol{T}_{\mathrm{cc}}\left({ }^{\circ} \mathrm{C}\right)$ \\
\hline PVC & 160 \\
XLPE & 250 \\
EPR & 250 \\
\hline
\end{tabular}

To protect an installation from short circuits, the following three conditions must be fulfilled [26]:

1) $I_{c u} \geqslant I_{P S C-M a x}$ : The cut-off power, $I_{\mathcal{C} u}$, of the protective element should be at least equal to the short-circuit current at the beginning of the conductor where it is installed, $I_{P S C-M a x}$. Most fault currents will be symmetrical three-phase short circuits at the beginning of the installation; it is a function of the characteristics of the transformer at the beginning of the installation.

$$
I_{P S C-M a x}=\frac{U_{p h}}{Z_{L}}
$$

2) $I_{P S C-\min } \geqslant I_{F 5}$ : The minimum permanent short-circuit intensity, $I_{P S C-\min }$, occurs at the end of the line in a phase-neutral fault, and must be greater than the fusion intensity for $5 \mathrm{~s}$ for the protection fuse, $I_{F 5}$ [33]. Physically, this means that it is within the time limits established for a short circuit $(<5 \mathrm{~s})$ and the energy-conservation equations in the adiabatic regime will be valid. The lower short-circuit current will be the one given for the fault in the phase-neutral loop:

$$
I_{P S C-\min }=\frac{C_{t} \cdot U_{p h}}{Z_{\text {Loop }}}
$$

where

$$
Z_{\text {Loop }}=2 \cdot Z_{L}=2 \cdot \sqrt{\left(\frac{C_{R} \cdot L}{K \cdot S}\right)^{2}+\left(X_{u} \cdot L\right)^{2}}
$$

The length limit, $L_{M a x_{-} I_{F 5}}$, for an installation by the above condition is given by Equation (11):

$$
L_{M a x_{-} I_{F 5}} \leqslant \frac{C_{t} \cdot U_{p h}}{2 \cdot I_{F 5} \cdot \sqrt{\left(\frac{C_{R}}{K \cdot S}\right)^{2}+\left(X_{u}\right)^{2}}}
$$

3) $(K \cdot S)^{2} \geqslant I_{t}^{2} \cdot t$ The thermal force admissible in the conductor, $(K \cdot S)^{2}$, must be greater than the energy that the protection device allows to pass through $\mathrm{I}_{\mathrm{t}}^{2} \cdot \mathrm{t}$; where $\mathrm{K}$ is a constant derived from the regulations [32] (Table 4).

Table 4. Value of the short-circuit constant $K$.

\begin{tabular}{ccc}
\hline Insulation & Copper (Cu) & Aluminum (Al) \\
\hline PVC & 115 & 74 \\
XLPE & 135 & 87 \\
EPR & 135 & 87 \\
\hline
\end{tabular}

\subsection{Proposed Variation to the Calculation Method}

As a hypotheses, the line length is equal to the maximum length given by the condition of the short circuit, Equation (11), and smaller than the maximum length admissible from the voltage drop condition (Equation (3)). The aim is to increase the capacity of the installation in terms of the short circuits limits, thus improving the maximum length of the installation and therefore the capacity of the 
distribution line to connect new users and/or GD. The solution proposed in the present work is to increase the neutral section in the final segment of the distribution grid (Figure 4). Specifically, in the case presented, the neutral conductor will be doubled, thereby duplicating the initial section.

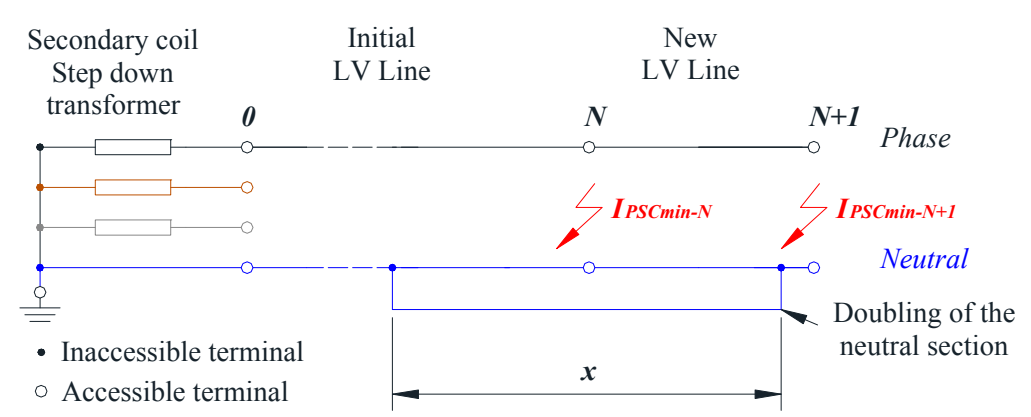

Figure 4. Radial distribution grid of modified LV.

Figure 4 shows that the distribution grid now includes $\mathrm{N}+1$ nodes and has increased its length, as $L_{N+1}$ is greater than $L_{N}$. The impedance of any phase-neutral fault loop and thus the intensity of the corresponding short circuit depends on the length, $x$, which requires that the neutral conductor doubles. As established in the hypotheses, if the minimum short circuit at node $\mathrm{N}$ takes the minimum value $\left(I_{F 5}\right)$ then, any lengthening desired of node $\mathrm{N}+1$ will be require a lengthening of the doubled neutral conductor, as reflected in Equation (12).

$$
\begin{aligned}
& R_{p h}+R_{n}=\frac{C_{R} \cdot L_{N+1}}{K \cdot S}+\left[\frac{C_{R} \cdot\left(L_{N+1}-x\right)}{K \cdot S}+\frac{C_{R} \cdot x}{K \cdot 2 \cdot S}\right] \stackrel{\text { Operand }}{\longrightarrow} R_{p h}+R_{n}=2 \cdot C_{R} \cdot R_{u} \cdot\left(L_{N+1}-\frac{x}{4}\right) \\
& X_{p h}+X_{n}=X_{u} \cdot L_{N+1}+\left[X_{u} \cdot\left(L_{N+1}-x\right)+X_{u} \cdot \frac{x}{2}\right] \stackrel{\text { Operand }}{\longrightarrow} X_{p h}+X_{n}=2 \cdot X_{u} \cdot\left(L_{N+1}-\frac{x}{4}\right) \\
& Z_{\text {Loop }}(x)=2 \cdot\left(L_{N+1}-\frac{x}{4}\right) \cdot \sqrt{\left(C_{R} \cdot R_{u}\right)^{2}+\left(X_{u}\right)^{2}} \Rightarrow I_{P S C \min }(x)=\frac{C_{t} \cdot U_{p h}}{Z_{\text {Loop }}(x)} \geqslant I_{F 5}
\end{aligned}
$$

The minimum length of the neutral line doubling, $x_{\min }$, must be such that on lengthening the line from $L_{N}$ to $L_{N+1}$, the fault in any modified phase-neutral loop is greater than or equal to the initial fault without modification; where, according to the hypotheses, takes the value of $I_{F 5}$.

$$
\begin{aligned}
& I_{P S C \min }\left(x_{\text {min }}\right) \geqslant I_{F 5} \rightarrow Z_{\text {Loop }}\left(x_{\text {min }}\right) \leqslant Z_{\text {Loop }}(0) \\
& 2 \cdot\left(L_{N+1}-\frac{x}{4}\right) \cdot \sqrt{\left(C_{R} \cdot R_{u}\right)^{2}+\left(X_{u}\right)^{2}} \leqslant 2 \cdot L_{N} \cdot \sqrt{\left(C_{R} \cdot R_{u}\right)^{2}+\left(X_{u}\right)^{2}} \\
& x_{\text {min }} \geqslant 4 \cdot\left(L_{N+1}-L_{N}\right)
\end{aligned}
$$

On the other hand, the maximum length of the neutral doubling, $x_{M a x}$, must be less than $L_{N+1}$, and the fault of any phase-neutral loop is lower than or equal to $I_{F 5}$ (Equation (14)).

$$
\begin{aligned}
& x_{\text {Max }} \leqslant L_{N+1} \\
& I_{P S C \min }\left(x_{M a x}\right) \geqslant I_{F 5} \rightarrow Z_{\text {Loop }}\left(x_{M a x}\right) \leqslant Z_{\text {Loop }}(0) \\
& 2 \cdot\left(L_{N+1}-\frac{x_{M a x}}{4}\right) \cdot \sqrt{\left(C_{R} \cdot R_{u}\right)^{2}+\left(X_{u}\right)^{2}} \leqslant 2 \cdot L_{N} \cdot \sqrt{\left(C_{R} \cdot R_{u}\right)^{2}+\left(X_{u}\right)^{2}}
\end{aligned}
$$

Finally, the maximum value that the line can increase from $L_{N}$ to $L_{N+1}$ is determined by operating in the inequality of Equation (14), giving:

$$
L_{N+1} \leqslant \frac{4}{3} \cdot L_{N}
$$




\section{Results}

Normalized calculation was applied as was the variation proposed for an underground LV distribution grid installed in conduit, according to the regulation [28] (Figure 2). The conductors used are made of aluminum, with insulation strength of $0.6 / 1 \mathrm{kV}$, and XLPE insulation; the sections used in this case study are $150 \mathrm{~mm}^{2}$ and $240 \mathrm{~mm}^{2}$, according to the particular norms of the distribution company [29].

\subsection{Length Line Calculation by the Normalized Method}

The study begins by calculating for overloads and it is considered that the line will be the maximum of its capacity for overloads, then, the minimum length line is calculated from the conditions of the voltage drop and short circuit.

\subsubsection{Overloads}

For the calculation of the maximum admissible intensity and of the corresponding correction factors, the Complementary Technical Instruction ITC-BT-07 of the regulation of low voltage RD $842 / 2002$ is used [28]. According to Equation (6), the diameter of the fuse fit the normative IEC 60269-1:2006 [33]. The fuses must meet the conditions of Equation (4). For each line section, the largest fuse that fulfilled these conditions is selected (Table 5). Thus, it fulfills the hypotheses of Section 2 and the load can reach the maximum intensity to overloads in the line.

Table 5. Overload conditions. Results of Equation (4).

\begin{tabular}{ccccccc}
\hline Section $\left(\mathbf{m m}^{\mathbf{2}}\right)$ & $\boldsymbol{I}_{\boldsymbol{t} \boldsymbol{b}} \mathbf{( A )}$ & $\boldsymbol{F c}$ & $\boldsymbol{I} \boldsymbol{z}(\mathrm{A})$ & $\boldsymbol{I}_{\boldsymbol{N}}(\mathrm{A})$ & $\boldsymbol{I}_{2}(\mathrm{~A})$ & $1.45 \boldsymbol{I}_{\boldsymbol{Z}} \mathbf{( A )}$ \\
\hline 150 & 230 & 1 & 230 & 200 & 320 & 333.5 \\
240 & 305 & 1 & 305 & 250 & 400 & 442.25 \\
\hline
\end{tabular}

\subsubsection{Voltage Drop Condition}

According to Table 5, the line is limited by the capacity of effective functioning of the fuse. Thus, the nominal power admitted by the line is adjusted to the nominal intensity of the fuse for each section. The nominal power for each case (Equation (16)) and the maximum length from voltage drop condition (Equation (3)) are shown in Table 6.

$$
P_{C}=\sqrt{3} \cdot U_{L} \cdot I_{N} \cdot \cos \varphi
$$

Table 6. Voltage drop. Results of Equation (3).

\begin{tabular}{cccccccc}
\hline Section $\left(\mathbf{m m}^{\mathbf{2}}\right)$ & $\boldsymbol{K}_{A L}\left(\mathbf{9 0}{ }^{\circ} \mathbf{C}\right)$ & $\boldsymbol{U}_{\boldsymbol{L}}(\mathrm{V})$ & $\boldsymbol{e}(\mathrm{V})$ & $\boldsymbol{P}_{C}(\mathrm{~W})$ & $\operatorname{tg}^{\prime}$ & $\boldsymbol{X}_{u}\left(\mathbf{\Omega} \cdot \mathbf{m}^{-\mathbf{1}}\right)$ & $L_{M a x-v d}(\mathbf{m})$ \\
\hline 150 & 28 & 400 & 22 & $1.10 \times 10^{5}$ & 0.75 & $1.0 \times 10^{-4}$ & 255 \\
240 & 28 & 400 & 22 & $1.38 \times 10^{5}$ & 0.75 & $1.0 \times 10^{-4}$ & 284 \\
\hline
\end{tabular}

\subsubsection{Short-Circuit Protection}

1) $I_{\mathcal{C} u} \geqslant I_{P S C-M a x}$ : The maximum intensity of short circuit, symmetrical three-phase fault, is given at the beginning of the distribution grid and it depends on the power of the distribution transformer. Here, has been considered a transformer of $630 \mathrm{kVA}$, where a fault will take an intensity of value (Equation (17)):

$$
\begin{aligned}
& I_{P S C-M a x}=\frac{U_{L}}{\sqrt{3} \cdot Z_{C C}} \stackrel{S=630 \mathrm{kVA}}{\longrightarrow} I_{P S C-M a x} \approx 24 \mathrm{kA} \\
& I_{P c u} \geqslant 24 \mathrm{kA}
\end{aligned}
$$


2) $I_{P S C-\min } \geqslant I_{F 5}$ : As can be seen in Table 7, this condition limits the maximum length of the distribution line (Equation (11)), as this is less than the maximum length per voltage drop (Equation (3)).

3) $(K \cdot S)^{2} \geqslant I_{t}^{2} \cdot t$ This condition of the short circuit is fulfilled. Further details are not given, since the length of the distribution line is not affected by this condition.

Table 7. Short-circuit conditions. Results of Equation (11).

\begin{tabular}{cccccccc}
\hline Section $\left(\mathbf{m m}^{\mathbf{2}}\right)$ & $\boldsymbol{U}_{\boldsymbol{L}}(\mathrm{V})$ & $C_{t}$ & $\boldsymbol{C}_{\boldsymbol{R}}$ & $\boldsymbol{I}_{\boldsymbol{N}}(\mathrm{A})$ & $\boldsymbol{I}_{\boldsymbol{F} 5}(\mathrm{~A})$ & $\boldsymbol{X}_{\boldsymbol{u}}\left(\boldsymbol{\Omega} \cdot \mathbf{m}^{-\mathbf{1}}\right)$ & $\boldsymbol{L}_{\mathbf{M a x}-I F 5}(\mathbf{m})$ \\
\hline 150 & 400 & 0.8 & 1.2 & 200 & 1250 & $1.0 \cdot 10^{-4}$ & 243 \\
240 & 400 & 0.8 & 1.2 & 250 & 1650 & $1.0 \cdot 10^{-4}$ & 272 \\
\hline
\end{tabular}

\subsection{Line Length Calculation with the Variation Proposed for the Grid Design}

As reflected in Table 7, the condition of minimum short circuit limits the maximum length of the distribution line under the hypotheses of Section 2 and according to Equation (11). With the doubling of the neutral section (Equation (12)), the length of the exploitation of the distribution line can lengthen up to what is established in Equation (15) (Table 8). This alternative design implies an increase in the line length more than $20 \%$.

Table 8. Admissible line length with the doubling of the neutral conductor section. Results of Equation (12).

\begin{tabular}{ccc}
\hline Section $\left(\mathbf{m m}^{\mathbf{2}}\right)$ & L Max-IF5 $_{\mathbf{M}}(\mathbf{m})$ & Line Length Increment (\%) \\
\hline 150 & 323 & $27 \% \leqslant 33 \%$ (Equation (15)) \\
240 & 329 & $21 \% \leqslant 33 \%$ (Equation (15)) \\
\hline
\end{tabular}

\section{Discussion}

The solution proposed would be applied to any installation where the maximum length reached by a voltage drop is greater than the maximum length reached by the least short circuit of the grid. Although, for greater simplicity, the calculation example was developed for a radial distribution grid with a single load, that is, with regard to Figure 1, it corresponds to the case in which $\mathrm{N}$ is equal to 1 ; and where the load implies the $100 \%$ of the thermal load capacity of the line.

From this standpoint, the length of the short circuit is increased, with margins sufficient to undertake the implementation of new users and/or DG in the line. This configuration does not use a new output of the step-down transformer; this is considered an advantage by being their limited number.

The fact of considering the same section for the neutral conductor as for the phases is to improve the logistics and installation of the distribution grid, as only one section was used for all the poles of the three-phase grid.

\section{Conclusions}

This paper proposes a simple solution, adjusted to the relevant regulations and embodied in a radial distribution grid of Spanish low voltage, to improve the interconnection of distributed generation, usually grid connected photovoltaic systems.

The solution proposed, i.e., the partial doubling of the neutral section, can increase the length of the use of a low voltage distribution generation by up to $20 \%$. This would improve the connection capacity of distribution grid installations as well as photovoltaic grid-connected systems, since in most cases these installations are installed over previously constructed distribution grids. 
Author Contributions: José Agüero-Rubio has carried out most of the work presented in this paper. Javier López-Martínez, José Ignacio Rojas-Sola and Ángel Jesús Callejón-Ferre have contributed with the entire manuscript critical revision and improving the introduction, conclusions and references sections.

Conflicts of Interest: The authors declare no conflict of interest.

\section{Abbreviations}

$C_{R} \quad$ Coefficient of resistance

$C_{t} \quad$ Coefficient of voltages

e Voltage drop, in $\mathrm{V}$

$F_{C} \quad$ Correlation factor for intensity, in A

$F_{c i} \quad$ Correction factor for installation

$F_{c t} \quad$ Correction factor for temperature

$I_{B} \quad$ Intensity of the circuit to protect, in A

$I_{\mathcal{C u}} \quad$ Cut-off power of the protection device, in A

$I_{F 5} \quad$ Fusion intensity for a fuse in $5 \mathrm{~s}$, in A

$I_{L} \quad$ Intensity of the line, in A

$I_{n} \quad$ Neutral current, in A

$I_{N} \quad$ Nominal intensity of the protection device, in A

$I_{P S C} \quad$ Permanent intensity of the short circuit, in A

$I_{t b} \quad$ Intensity consulted from normalized tables in A

$I_{Z} \quad$ Maximum intensity of the normalized channeling, in A

$K \quad$ Conductivity of the conductor, in $\Omega^{-1} \cdot \mathrm{mm}^{-2} \cdot \mathrm{m}$

$L_{j} \quad$ Total length from node 0 to node $\mathrm{j}$, in $\mathrm{m}$

$P_{C} \quad$ Calculated power, in $\mathrm{W}$

$P_{N} \quad$ Nominal power, in $\mathrm{W}$

$S \quad$ Section of a conductor, in $\mathrm{mm}^{2}$

$R_{L} \quad$ Resistance of a line, in $\Omega$

$R_{n} \quad$ Neutral resistance, in $\Omega$

$R_{p h} \quad$ Resistance of a phase, in $\Omega$

$R_{u} \quad$ Unit resistance, in $\Omega \cdot \mathrm{m}^{-1}$

$\varphi \quad$ Difference between voltage and phase intensity, in rad

$\cos \varphi \quad$ Power factor of value 0.8 in this research

$U_{p h} \quad$ Voltage between phase and neutral, in $\mathrm{V}$

$U_{L} \quad$ Line voltage, in $\mathrm{V}$

$X_{L} \quad$ Inductive impedance of the line, in $\Omega$

$X_{n} \quad$ Inductive impedance of the neutral, in $\Omega$

$X_{p h} \quad$ Inductive impedance of the phase, in $\Omega$

$X_{u} \quad$ Unit inductive impedance, in $\Omega \cdot \mathrm{m}^{-1}$

$Z_{C C} \quad$ Short-circuit impedance of the distribution transformer

$Z_{L} \quad$ Line impedance, in $\Omega$

$Z_{\text {LOOP }}$ Impedance of the phase-neutral loop, in $\Omega$

\section{References}

1. European Parliament. Directive 2009/28/EC of the European Parliament and of the Council of 23 April 2009 on the promotion of the use of energy from renewable sources and amending and subsequently repealing Directives 2001/77/EC and 2003/30/EC. Off. J. Eur. Union L 2009, 140, 16-47.

2. IDAEt. Institute for Energy Diversification and Saving. Renewable Energy Plan, 2011-2020. Ministry of Industry, Tourism and Trade. 2011. Available online: http://www.idae.es/index.php/id.670/relmenu.303/ mod.pags/mem.detalle (accessed on 4 March 2016).

3. Montoya, F.G.; Aguilera, M.J.; Manzano-Agugliaro, F. Renewable energy production in Spain: A review. Renew. Sustain. Energy Rev. 2014, 33, 509-531. [CrossRef]

4. Battaglini, A.; Lilliestam, J.; Haas Patt, A. Development of SuperSmart Grids for a more efficient utilization of electricity from renewable sources. J. Clean. Product. 2009, 17, 911-918. [CrossRef]

5. Ghassan, Z. Technolgy mix alternatives with high shares of wind power and photovoltaics-case study for Spain. Energy Policy 2011, 39, 8070-8077.

6. Castellano, N.N.; Gázquez Parra, J.A.; Valls-Guirado, J.; Manzano-Agugliaro, F. Optimal displacement of photovoltaic array's rows using a novel shading model. Appl. Energy 2015, 144, 1-9. [CrossRef] 
7. Fernández-García, A.; Rojas, E.; Pérez, M.; Silva, R.; Hernández-Escobedo, Q.; Manzano-Agugliaro, F. A parabolic-trough collector for cleaner industrial process heat. J. Clean. Prod. 2015, 89, 272-285. [CrossRef]

8. Viral, R.; Khatod, D.K. Optimal planning of distributed generation systems in distribution system: A review. Renew. Sustain. Energy Rev. 2012, 16, 5146-5165. [CrossRef]

9. Hong, Y.Y.; Lai, Y.M.; Chang, Y.R.; Lee, Y.D.; Liu, P.W. Optimizing capacities of distributed generation and energy storage in a small autonomous power system considering uncertainty in renewables. Energies 2015, 8, 2473-2492. [CrossRef]

10. Agüero-Rubio, J.; Giménez-Fernández, A.; Callejón-Ferre, A.J.; López-Martínez, J. Simple rule for management of thermal loads with real-time prices. J. Clean. Prod. 2014, 78, 48-53. [CrossRef]

11. Rosehart, W.; Cañizares, C.; Quintana, V. Costs of Voltage Security in Electricity Markets. In Proceedings of the IEEE/PES Summer Meeting, Seattle, WA, USA, 16-20 July 2000.

12. Thomson, M.; Infield, D.G. Impact of widespread photovoltaics generation on distribution systems. IET Renew. Power Syst. 2007, 1, 33-40. [CrossRef]

13. Hermoso-Orzáez, M.J.; Rojas-Sola, J.I.; Gago-Calderón, A. Electrical consequences of large-scale replacement of metal halide by LED luminaires. Light. Res. Technol. 2016. [CrossRef]

14. Gianni, C.; Ghiani, E.; Mocci, S.; Pilo, F. A Multiobjetive Evolutionary Algorithm for the Sizing and Siting of Distributed Generation. IEEE Trans. Power Syst. 2005, 20, 750-757.

15. Haesen, E.; Driesen, J.; Belmans, R. Robust planning methodology for integration of stochastic generators in distribution grids. IET Renew. Power Gener. 2007, 1, 25-32. [CrossRef]

16. Hernández, J.C.; Mediana, A.; Jurado, F. Optimal allocation and sizing for profitability and voltage enhancement of PV systems on feeders. Renew. Energy 2007, 32, 1768-1789. [CrossRef]

17. Baños, R.; Manzano-Agugliaro, F.; Montoya, F.G.; Gil, C.; Alcayde, A.; Gómez, J. Optimization methods applied to renewable and sustainable energy: A review. Renew. Sustain. Energy Rev. 2011, 15, 1753-1766. [CrossRef]

18. Sánchez, P.; Montoya, F.G.; Manzano-Agugliaro, F.; Gil, C. Genetic algorithm for S-transform optimisation in the analysis and classification of electrical signal perturbations. Expert Syst. Appl. 2013, 40, 6766-6777. [CrossRef]

19. Montoya, F.G.; Manzano-Agugliaro, F.; López, J.G.; Alguacil, P.S. Power quality research techniques: Advantages and disadvantages. DYNA 2012, 79, 66-74.

20. Boletín Oficial del Estado (BOE). Royal Decree 436/2004, Dated 12 March 2004, Establishing the Methodology for the Updating and Systematisation of the Legal and Economic Regime of Activity of Production of Electrical Energy in Special Regime; BOE No. 75; BOE: Madrid, Spain; 27 March 2004; pp. 13217-13238.

21. Boletín Oficial del Estado (BOE). Royal Decree 661/2007, Dated 25 May 2007, Regulates Spain's Energy Sector and the Production of the Nation's Electricity Supply under a Special Regime; BOE No. 126; BOE: Madrid, Spain; 26 May 2007; pp. 22846-22886.

22. Del-Río, P.; Mir-Artigues, P. Support for solar PV deployment in Spain: Some policy lessons. Renew. Sustain. Energy Rev. 2012, 16, 5557-5566. [CrossRef]

23. Movilla, S.; Miguel, L.J.; Blazquez, L.F. A systems dynamics approach for the photovoltaic energy market. Energy Policy 2013, 60, 142-154. [CrossRef]

24. Ruiz-Romero, S.; Colmenar-Santos, A.; Mur-Pérez, F.; Lopez-Rey, A. Integration of distributed generation in the power distribution network: The need for smart grid control systems, communication and equipment for a smart city-Use cases. Renew. Sustain. Energy Rev. 2014, 38, 223-234. [CrossRef]

25. Papaioannou, I.T.; Purvins, A. A methodology to calculate maximum generation capacity in low voltage feeders. Int. J. Electr. Power. Energy Syst. 2014, 57, 141-147. [CrossRef]

26. Dmelect, S.L. Software for installations 2005. Theory of Low Voltage Electrical Installations. 2005. Available online: http:/ / www.dmelect.com/ (accessed on 26 May 2016).

27. Guirado-Torres, R.; Asensi-Orosa, R.; Jurado-Melguizo, F.; Carpio-Ibáñez, J. Electric Technology; McGrawHill: New York, NY, USA, 2006; ISBN: 84-481-4007-X.

28. Boletín Oficial del Estado (BOE). Royal Decree 842/2002, Dated 2 August 2002, Electro-technical Regulation for Low Voltage and and its Technical Specifications; BOE No. 224; BOE: Madrid, Spain; 18 September 2002; pp. 33084-33086. 
29. Endesa, S.A. Particular Rules and Technical and Safety Conditions Sevillana-Endesa. 2005. Available online: http://www.endesa.com/es/proveedores/normativaycondicionescontratacion/home?folder= 47572da5-b001--4c2e-9f3a-3ba725ea3251 (accessed on 12 March 2016).

30. Schneider Electric España S.A. Electrical Installation Guide according to International Standards IEC; MerlínGerin: Madrid, Spain, 2005; ISBN: 84-609-8658-6.

31. Low-Voltage Electrical Installations-Part 4-43: Protection for Safety-Protection against Overcurrent; IEC 60364-4-43:2008/Corr.:2008; Equivalent to UNE-HD 60364-4-43:2013; IEC: Geneva, Switzerland, 2008.

32. Electrical Installations of Buildings_Part 5: Selection and Erection of Electrical Equipment-Section 523: Current-Carrying Capacities in Wiring Systems; IEC 60364-5-523:1999; IEC: Geneva, Switzerland, 1999.

33. Low-Voltage Fuses_Part 1: General Requirements; IEC 60269-1:2006; IEC: Geneva, Switzerland, 2006.

(C) 2016 by the authors; licensee MDPI, Basel, Switzerland. This article is an open access article distributed under the terms and conditions of the Creative Commons Attribution (CC-BY) license (http://creativecommons.org/licenses/by/4.0/). 